$\mathbf{R}_{\text {ESEARCH }} \mathbf{P}$

aper
FOOD SCIENCE RESEARCH JOURNAL
- Visit us : www.researchjournal.co.in Volume 9 | Issue 2 | October, 2018 | 431-433

DOI : $10.15740 / \mathrm{HAS} / F S R J / 9.2 / 431-433$

\title{
Rejuvenating millets through value addition
}

\author{
Prema B. Patil
}

Millets have been traditionally the main components of the food basket of the poor in India. They have been known for their rich nutrient contents and drought resistance quality. The study was conducted in Kohlar village of Bagewadi taluk of Vijayapura district, Karnataka state. Three value added products such as foxtail millet bisibelebath, Little millet paddu and finger millet malt were demonstrated to the farm women and its acceptability was tested. The overall acceptability of the products revealed that foxtail millet bisibelebath scored 4.4 compared to rice bisibelebath which obtained a score of 4.6. The comparison between little millet products revealed that little millet paddu obtained a score of 4.7 compared to rice paddu which was scored 4.4 out of 5. Further comparison of finger millet products revealed a score of 4.6 for finger millet malt compared to the ready-to-cook malt product obtained from the market which was scored 4.4 out of 5 .

Key Words : Rejuvenation, Millets, Processing, Value addition, Acceptability

How to cite this article : Patil, Prema B. (2018). Rejuvenating millets through value addition. Food Sci. Res. J., 9(2): 431-433, DOI : 10.15740/HAS/FSRJ/9.2/431-433. Copyright@ 2018: Hind Agri-Horticultural Society. 